Cuadernos de Historia Contemporánea

ISSN: 0214-400X

http://dx.doi.org/10.5209/CHCO.56265

\title{
Miguel de Unamuno: La feminización de la masculinidad moderna ${ }^{1}$
}

\author{
José Javier Díaz Freire²
}

Recibido: 17 de octubre de 2016 / Aceptado: 23 de marzo de 2017

Resumen. Miguel de Unamuno y Ortega discreparon durante el primer tercio del siglo XX sobre el proceso de modernización que se estaba produciendo en España. Ambos lo interpretaron en términos de género. Pero mientras Ortega vinculaba la crisis de la modernidad con un déficit de masculinidad, Unamuno entendía que la deshumanización del mundo moderno se debía a una conformación inadecuada de la feminidad y de la masculinidad de la época, que cabía corregir feminizando la modernidad. Para ello emprendió una intensa labor de crítica de las relaciones de género en su obra dramática y novelesca que era también una propuesta de construcción de una modernidad alternativa.

Palabras clave: Modernidad; género; masculinidad; deshumanización.

\section{[en] Miguel de Unamuno: The Feminization of Modern Masculinity}

\begin{abstract}
Unamuno and Ortega defended different points of view about the modernity crisis at the begining of the 20th Century. Their main concern was about gender relations but, while Ortega thought that the solution to the modern crisis was to restore masculinity, Unamuno claimed that in order to build a more humane modernity a different masculinity was necessary. The key to achieve this goal was to blend masculinity and femininity in a new gender identity.
\end{abstract}

Keywords: Modernity; gender; masculinity; dehumanization.

Sumario. Introducción. 1. Ortega. Modernidad resignada y masculinidad. 2. Unamuno. Una modernidad maternal. 3. Propuesta de Unamuno. La crítica alegórica de la masculinidad y la feminidad. 4. Conclusión. 5. Referencias bibliográficas.

Cómo citar: Díaz Freire, J. J. (2017). "Miguel de Unamuno: La feminización de la masculinidad moderna". Cuadernos de Historia Contemporánea, 39, 39-58.

1 El presente trabajo se inscribe dentro del Grupo de Investigación Universitaria de la UPV/EHU titulado: "La experiencia de la sociedad moderna en España, 1870-1990, GIU14/04, la UFI 11/27 y el proyecto del MICINN código: HAR2012-37959-C02-01.

2 Universidad del País Vasco UPV/EHU (España)

E-mail: josejavier.diazfreire@ehu.es 


\section{Introducción}

Dijo Ortega, al conocer la noticia de su fallecimiento, que Unamuno había muerto de "mal de España" 3 . Se trataba, con toda seguridad, de un postrer reconocimiento a quien había sido un formidable oponente precisamente en esa tarea de denunciar los males nacionales. Ambos habían protagonizado un sonoro enfrentamiento que se alargó entre 1909 y 1911. Se trataba de un episodio más de la querella entre hispanizantes y europeizantes que es bien conocido, pero que, leído desde la perspectiva de género, arroja un aspecto sobre el que quizás no se ha reparado bastante: la polémica se produce en los términos de una disputa entre masculinidades.

Todo comienza con una carta de Unamuno a Azorín publicada en el $A B C$, donde el escritor bilbaíno califica de "papanatas" a los que, según afirmaba, estaban "bajo la fascinación de los europeos"4. El artículo provocó una airada respuesta de Ortega. El contenido de género resulta obvio si recordamos que Ortega, en su réplica, denunció los que llamaba "usos jaquescos" de Unamuno. Le estaba atribuyendo una masculinidad no moderna; jaque, que significa algo así como perdonavidas o retador, era uno de los atributos del don Juan. Y lo reforzaba comparándolo con los mozos que, matizaba en los "pueblos castizos", daban un trancazo sobre el candil que iluminaba la fiesta por la noche para desencadenar una pelea. Se decía, además, tentado a "contestar con algún vocablo tosco", y aunque calificaba a Unamuno como "energúmeno español", afirmaba optar por mantenerse dentro de los límites de la "buena educación"5. Esto es, dentro de los parámetros de una masculinidad respetable.

Para Unamuno la pugna también lo era entre masculinidades, rechazando los contornos de esa masculinidad moderna que defiende Ortega, mientras afirmaba que defendía su postura conservando tres cualidades: "la seriedad, la falta de pose, la sencillez", y que a la falta de "sentido de la reclamé, oponía su "altivez". Esta postura de rechazo se vuelve todavía más clara cuando postula que hay que "revolverse contra esos estetas deportistas", pues el deporte se había convertido en unos de los rasgos de la nueva masculinidad, y cuando enuncia el conocido "que inventen ellos" con la justificación de que, según decía, "acaso esto es más señor", es decir, más propiamente masculino ${ }^{6}$. Además, en la conclusión de Del sentimiento trágico de la vida, donde como se ha dicho continua su diálogo con Ortega, Unamuno afirmaba hablar desde España, definida como "hogar del ideal caballeresco"7.

Que la pugna por la solución que había de darse a los problemas de España se entablase en términos de enfrentamiento entre modelos de masculinidad, una masculinidad moderna que defiende Ortega y otra que, sin precisarlo ahora, parece conservar algunos rasgos aristocráticos, está lejos de ser anecdótico. Es, por el contrario, una constante de todo el período. En efecto, los proyectos de reconstrucción nacional que

3 Ortega y Gasset, José: "En la muerte de Unamuno", en Antonio Sánchez Barbudo (ed.): Miguel de Unamuno, Barcelona, Crítica, 1980 (1ª ed. 1974), p. 19.

4 Unamuno, Miguel de: "De Unamuno", $A B C, 15$ de septiembre de 1909, p. 10.

5 Todas las citas de Ortega en Ortega y Gasset, José: "Unamuno y Europa, fábula", en Obras Completas, t. I, Fundación José Ortega y Gasset y Taurus, Madrid, 2004, p. 256 (publicado inicialmente en El Imparcial, 27 de septiembre de 1909, p. 3).

6 Unamuno, Miguel de: "De Unamuno", p. 10.

7 Unamuno, Miguel de: Del sentimiento trágico de la vida en los hombres y en los pueblos y Tratado del amor de Dios, Tecnos, Madrid, 2005, p. 473. Que Unamuno alude en esta obra al diálogo con Ortega fue señalado por primera vez por Emilio Salcedo en "Unamuno y Ortega y Gasset, diálogo entre dos españoles", Cuadernos de la Cátedra Miguel de Unamuno, 7 (1956), p. 105. 
se oponen desde el final del siglo XIX hasta la guerra civil incluyen diferentes proyectos de reconstrucción de la masculinidad, lo que abunda en la idea, ya conocida, del vínculo entre los contornos del cuerpo de la nación y del cuerpo de los hombres ${ }^{8}$. Lo que quizás resulta más novedoso es señalar que, dado que esas soluciones remiten a modelos diferentes de modernización, la pugna entre esos programas diferentes de modernización se verifica en gran parte como una oposición entre diferentes modelos de masculinidad. Esto otorga a la dimensión de género un tamaño superior al que normalmente se le atribuye, pues la masculinidad aparece como el entero programa de modernización y de construcción nacional.

Puede observarse en las propuestas respectivas de Unamuno y Ortega durante la década de los veinte y treinta que parecen dialogar entre sí sin llegar a cruzarse. Se trata, sobre todo, de España invertebrada y La rebelión de las masas, pero también de El tema de nuestro tiempo y ¿Qué es la filosofía? de Ortega, y de un conjunto de novelas de Unamuno entre las que cabe destacar, como más significativas, Abel Sánchez, Tres novelas ejemplares y un prólogo y El otro, a las que cabría añadir El hermano Juan, La tía Tula y San Manuel Bueno o Niebla, esta última algo anterior. En conjunto, estas obras muestran un modelo de masculinidad que se corresponde respectivamente con un concepto de modernidad que cabría llamar restaurativa, en el caso de Ortega, y otro que se ajusta al término de alternativa, para Unamuno. El mismo calificativo valdría lógicamente para la masculinidad que defienden. Y precisamente esa afinidad puede ayudar a valorar su contenido. La modernidad restaurativa que Ortega defiende para España lo es en tanto que plantea, en un primer momento, la asimilación a Europa y, en el contexto de crisis provocado en el período de entreguerras, porque señala como solución la negación de las negaciones que contiene la modernidad por medio de una restauración del orden de género. La propuesta de Unamuno, por el contrario, busca la rectificación de la modernización a través de una nueva construcción de España, lo que significa también un nuevo orden de género. Eso exige a su punto de vista una gran agudeza en términos de género: en efecto, la crítica unamuniana se caracteriza por su capacidad para diseccionar los elementos constituyentes de la masculinidad y por su voluntad de proponer una reordenación alternativa de los mismos. La entidad de la propuesta de Unamuno aconseja destinarle un espacio suplementario en este texto. Por eso, después de los apartados 1 y 2 , que examinan los programas de reforma de la masculinidad y la modernidad de Ortega y Unamuno, y que actúan a modo de telón de fondo, se destina todo el apartado 3 a abordar la crítica a que el escritor bilbaíno somete las relaciones de género y que le conducirá a la defensa de una masculinidad feminizada.

\section{Ortega. Modernidad resignada y masculinidad}

Para Ortega, urgía una rectificación de la modernidad que creía vislumbrar ya durante los años veinte: en El tema de nuestro tiempo, de 1921, constata así "la iniciación

8 Ver, por ejemplo: Reeser, Todd W., Masculinities in Theory: An Introduction, Chichester Malden, Wiley-Blackwell, 2011, pp. 174 y passim. También Yuval-Davis, Nira: Gender and Nation, Londres, SAGE Publications, 1997, p. 23 y Sluga, Glenda: "Masculinities, nations, and the new world order: Gendered discourses on peacemaking and nationality in Britain, France and the United States after the First World War", en Stefan Dudink, Karen Hagemann and John Tosh (eds.): Masculinities in Politics and War. Gendering the Modern History, Manchester y Nueva York, Manchester University Press, p. 240. 
de una mecánica espiritual nueva"9 que vendría a corregir la modernidad, un proceso que al final de la década, llega a afirmar, "ha concluido" 10 . No obstante, en la mayor parte de las ocasiones, la clausura de la modernidad aparece en su obra como una tarea a realizar, como el tema de ese momento histórico: "nuestra época necesita, desea superar la modernidad"11. Con esas afirmaciones, Ortega se muestra muy alejado de su propio pensamiento anterior a la Primera Guerra Mundial y pasa a nutrir las filas de aquellos pensadores críticos con la modernidad ${ }^{12}$; incluso parece aproximarse en algunas formulaciones a Unamuno, también crítico con la misma, aunque el antimodernismo de Ortega es, sobre todo, y a diferencia del de Unamuno, preventivo de la revolución social.

En su opinión, la modernidad conducía a la revolución en la forma de la invertebración o la rebelión de las masas debido al idealismo constitutivo del pensamiento moderno. La que denomina "magnífica tesis idealista inspiradora de la modernidad" se vuelve subjetivismo y, al hacerlo, aboca a la sociedad a unas expectativas sin freno que solo pueden acabar en desilusión. Al "alma revolucionaria" le sucederá, afirmaba, un "alma desilusionada"13. Este es así su pronóstico, el fin próximo de la modernidad con una fase intermedia de desmoralización, de fracaso de las masas en sus pretensiones de transformación y democratización de la sociedad. Pero esta etapa de resignación tendría unas consecuencias inmediatas sobre la masculinidad y la nación. El país perdería población "no tanto por hambre, peste u otros reveses, cuanto porque disminuye el poder genesíaco del hombre" y, además, con esa disminución de la virilidad "mengua el coraje civil. (Y) comienza el reinado de la cobardía"14. La quiebra de la masculinidad no era la única consecuencia desde el punto de vista de género del desarrollo de la modernidad. El mismo triunfo del idealismo ya la amenazaba porque provocaba una cierta indiferenciación entre los sexos oscureciendo "ese tú, el más distinto de mí, que es el tú que es ella"15.

La modernidad se presentaba así como contraria al orden de género y ello daba coherencia a la pertinaz defensa que Ortega hacía de la figura del don Juan en su artículo de 1921 "Introducción a un Don Juan", donde se apartaba de sus críticos diciendo que, si bien había tenido "mala prensa", esta debía "bastar para que sospechemos en él las más selectas cualidades". No cabe duda de que, en su ensayo, Ortega estaba defendiendo una determinada concepción de la masculinidad y un determinado orden de género en lo que definía como "condensación ejemplar de la experiencia masculina" 16 . De hecho, en torno al don Juan se estaba articulando durante los años veinte y treinta un debate sobre el orden de género provocado por el desorden sexual iniciado a finales de siglo y que se intensificó después de la Gran Guerra. Además,

9 Ortega y Gasset, José: El tema de nuestro tiempo, Madrid, Revista de Occidente, 1974 (1ª edic. 1923), p. 131.

10 Ortega y Gasset, José: Qué es filosofía, Madrid, Revista de Occidente en Alianza Editorial, 1989, p. 127.

11 Ortega y Gasset, José: Qué es filosofia..., p. 156.

12 Ver Dust, Patrick H., Ortega y Gasset and the Question of Modernity, Minneapolis, University of Minnesota Press, 1989. Los distintos autores coinciden en el entusiasmo de Ortega por la modernización anterior a la Primera Guerra Mundial y el cambio de su actitud posterior, pero no en el alcance de la crítica orteguiana a la modernidad; Wlad Godzich, uno de ellos, afirma: "a pesar de los planteamientos de algunos de los colaboradores de este libro, destacadamente Morón Arroyo, es claro que Ortega no era un posmoderno”, p. 371 (traducción propia).

13 Ortega y Gasset, José: El tema..., p. 132.

14 Ortega y Gasset, José: El tema..., p. 147.

15 Ortega y Gasset, José: Qué es filosofia..., p. 154.

16 Ortega y Gasset, José: "Introducción a un Don Juan”, en Obras Completas, t. VI, p. 125. Lo anterior en p. 133. 
Ortega situó al don Juan como opuesto a la modernidad. Aunque la argumentación resulte alambicada, en el capítulo sexto de El tema de nuestro tiempo colocaba el desarrollo de la cultura europea entre las figuras antitéticas de Sócrates y don Juan, siendo Sócrates la encarnación de la razón que desembocará en la razón moderna y don Juan un aliado de la vida. "Don Juan se revuelve contra la moral -señalaba entonces-, porque la moral se había antes sublevado contra la vida". En ¿Qué es filosofía? también lo alude. Así, dado que rechaza la cultura griega como comienzo del racionalismo e idealismo modernos, exhorta: "Imitemos de Grecia sólo a Ulises, y de Ulises sólo la gracia con que sabía escapar a los encantos de Circe y Calipso", es decir, en la medida en que era un burlador de mujeres; por eso aclara: "Ulises es el primer Don Juan"17.

Ortega definía la nación como "una masa humana organizada, estructurada por una minoría de individuos selectos"18. Esta concepción hacía todavía más perentorio su diagnóstico de España como nación invertebrada, pues el calificativo se refería precisamente a la falta de unión entre la élite y las muchedumbres provocada por la rebelión de las masas. La invertebración histórica se producía "cuando en una nación la masa se niega a ser masa", algo que consideraba contrario al orden inmutable de las cosas -"tan absurdo como sería querer reformar el sistema de las órbitas siderales"- y que observaba a su alrededor: "En España - decía- vivimos hoy entregados al imperio de las masas"19. Al igual que Unamuno, pero en un sentido muy distinto de este, Ortega extendería su diagnóstico de España al conjunto europeo. Por esta razón, se ha dicho que España invertebrada es la rebelión española de las masas. Los diagnósticos en ambos libros son congruentes y las argumentaciones que exhiben se refuerzan mutuamente, mostrando que lo que en definitiva estaba en disputa era el proceso de modernización.

El libro España invertebrada aparece atravesado por una disyuntiva que Ortega formula enfáticamente: “¿No hay hombres, o no hay masas?”, se pregunta en el título de uno de los capítulos ${ }^{20}$. Con esta pregunta, el filósofo buscaba clarificar el completo problema de la invertebración de España, pues como afirmaba, "en el hueso de esa sencilla frase" se puede "reconstruir el esqueleto entero del espíritu público español durante los años corrientes" 21 . La respuesta que ofrece resulta un tanto errática o dubitativa, quizás debido a que no quiere justificar el ascenso de las masas. Así, niega primero que falten hombres, ya que su ausencia es, en realidad, un producto de la falta de disposición de las muchedumbres para reconocer su liderazgo. No hay hombres, o han desaparecido, viene a decir, porque "las masas no quieren ser masas" 22 . Lo que implicaba definir la hombría como la capacidad para representar a la muchedumbre: "la hombría ... no consiste en las dotes que la persona tiene, sino precisamente en las que el público, la muchedumbre, la masa pone sobre ciertas

17 Ortega y Gasset, José: Qué es filosofia, pp. 161-162.

18 Ortega y Gasset, José: España invertebrada, Madrid, Espasa-Calpe, 1984 ( $1^{\mathrm{a}}$ ed. 1964), p. 99. Ortega insiste en esta idea definiendo nación como "la unión hipostática del Poder público y la colectividad por él regida", en Ortega y Gasset, José: La rebelión de las masas, Barcelona, Planeta Agostini, 1985, p. 179.

19 Ortega y Gasset, José: España invertebrada, respectivamente pp. 100, 109 y 102. La referencia de Ortega al cosmos es sorprendente porque era muy consciente de los cambios en la visión del universo provocados por los avances de la física: sobre todo por la teoría de la relatividad. Demuestra su esfuerzo denodado por restaurar el orden social.

20 Ortega y Gasset, José: España invertebrada, p. 91.

21 Ortega y Gasset, José: España invertebrada, p. 93.

22 Ortega y Gasset, José: España invertebrada, p. 97. 
personas" ${ }^{23}$. Pero en un momento posterior coloca esa hombría en las cualidades propias del líder y el problema de España en la "evidente y perdurable escasez de individuos eminentes" ${ }^{24}$. También ensaya fórmulas de conciliación entre los dos argumentos: "la rebelión sentimental de las masas, el odio a los mejores, la escasez de éstos -he ahí la razón verdadera del gran fracaso histórico". En cualquier caso, la razón última del retraso español se hacía depender de una determinada conformación de la masculinidad y, por ello, la tarea no dejaba lugar a dudas: "Hay que ponerse a forjar un nuevo tipo de hombre español'"25.

Ortega no señaló las características de este nuevo hombre español, más allá de ese rasgo ya apuntado de indocilidad y de considerar que "ha ido desmedrando"26 y perdiendo vitalidad. Pero sí podemos profundizar en el tipo de hombre que rechaza en La rebelión de las masas, donde dice que se propone hacer la "anatomía del hombre hoy dominante" ${ }^{27}$. La génesis del mismo la remite a las características del proceso de modernización: “¿qué insuficiencias radicales padece la cultura europea moderna? -se pregunta-. Porque es evidente que, en última instancia, de ellas proviene esta forma humana hoy dominante" 28 . La masculinidad que busca perfilar y condenar es la del hombre-masa rebelde y la encuentra, paradójicamente, más desarrollada en los países mediterráneos. La emergencia de este tipo de hombre habría venido acompañada, en su opinión, de una erosión de todas las diferencias sociales, una de cuyas manifestaciones más evidentes es la igualdad entre los sexos y otra el predominio de la juventud, al que acompañó el culto al cuerpo, fenómenos todos ellos que remite, acertadamente, al fin de siècle, aunque se intensificaron después de la Primera Guerra Mundial. "Se nivelan las fortunas, se nivela la cultura entre las distintas clases sociales, se nivelan los sexos", constataba acerbamente ${ }^{29}$.

Madariaga percibió tras la guerra y hasta 1945 "un cambio radical en las costumbres femeninas" ${ }^{30}$. Otros pensadores, debido a ello, caracterizaron el período del entreguerras como de predominio femenino -Eugenio d'Ors lo nombró como "mundo-mujer"'31. En opinión de Ortega, en cambio, los años veinte eran una etapa, paradójicamente masculina, pero con un predominio de los hombres jóvenes. Conciliaba de esta manera el cambio en las costumbres femeninas, que interpretaba como de "asimilación al hombre" -"ahora la mujer va desnuda como un muchacho", decía--32 y el cambio en los parámetros sobre los que se construía la masculinidad y que, como ya señalara Rotundo para los Estados Unidos, apuntaban a una masculinidad basada

23 Ortega y Gasset, José: España invertebrada, p. 94.

24 Ortega y Gasset, José: España invertebrada, p. 126.

25 Ortega y Gasset, José: España invertebrada, p. 159. El entrecomillado anterior en p. 154.

26 Ortega y Gasset, José: España invertebrada, p. 154.

27 Ortega y Gasset, José: La rebelión..., p. 37. Nerea Aresti identifica en el período de entreguerras un "empeño por definir lo que significaba ser un hombre" con fundamentalmente dos tipos de propuestas: una liberal, que se planteaba renovar y secularizar los ideales de género, y otra frecuente entre los sectores más afines al régimen primoriverista que planteaba que se había "desvirtuado el verdadero significado de la masculinidad española", en Aresti, Nerea: "Masculinidad y nación en la España de los años 1920 y 1930”, Mélanges de la Casa de Velázquez , 42-2 (2012), pp. 58-62. La posición de Ortega, a pesar de su oposición a Primo de Rivera, cabe colocarla en este segundo lugar.

28 Ortega y Gasset, José: La rebelión..., p. 197.

29 Ortega y Gasset, José: La rebelión..., p. 55.

30 Madariaga, Salvador de: Mujeres españolas, Madrid, Espasa-Calpe, 1991, p. 46.

31 D'Ors, Eugenio: Lo barroco, Madrid, Tecnos, 1993, p. 31.

32 Ortega y Gasset, José: La rebelión..., p. 274-275. 
en el logro individual y en el cuerpo ${ }^{33}$. De este modo, aunque salvaba el predominio masculino, su diagnóstico no se apartaba de la denuncia de la desestabilización del orden sexual y social. Resumiendo las tesis del ensayo, Ortega afirmaba que Europa estaba desmoralizada debido a la rebelión de las masas, lo que se traducía en una desconfianza hacia la ideología de progreso y una provisionalidad del presente que daba lugar a que: "ni los hombres saben bien a qué instituciones de verdad servir, ni las mujeres que tipo de hombres prefieren de verdad"34.

Ambos fenómenos eran muy graves. Pero quizás se agravaban del lado femenino, porque esta incapacidad de las mujeres para elegir atinadamente un hombre amenazaba la misma esencia de la feminidad. En opinión de Ortega, "la mujer, cuando lo es en plenitud, es siempre bella durmiente del bosque vital que necesita ser despertada", no por un príncipe azul, sino, aunque parezca extraño, por un "tipo genérico de perfección masculina". Es decir, por un modelo de masculinidad o, en realidad, por un hombre que encarne ese modelo. Por eso, hasta que lo encuentra, la mujer permanece dormida y camina "sonámbulicamente" buscándolo ${ }^{35}$. Todo ello explica que la incapacidad de las mujeres para elegir adecuadamente a un compañero esté lejos de ser una cuestión meramente privada y justifica determinadas manifestaciones de Ortega en las que señalaba la prioridad de una reforma de lo que denominaba el "alma femenina": "no pocos defectos capitales, persistentes de la existencia hispánica, cuyo origen se busca en las causas más abstrusas -afirmaba-, provienen sencillamente de la insuficiente feminidad española" ${ }^{36}$.

La solución que proponía Ortega para España, para Europa y para la misma modernidad era, en definitiva, una reordenación de las relaciones de género que implicaba atajar los cambios en la definición de masculinidad y feminidad que se habían producido sobre todo después de 1914. Los hombres, se infería, debían seguir a los mejores y las mujeres a hombres maduros en los que predominara el espíritu sobre el cuerpo; un tipo de hombre similar al que él mismo representaba. Se trataba del mismo modelo, además, que haría posible la "supernación europea" que proponía, con el nuevo tipo de modernidad que, en su opinión, alumbraba. La vida actual, decía, "es fruto de un interregno, de un vacío entre dos organizaciones del mundo histórico. La que fue, la que va a ser" ${ }^{37}$. Esta rectificación de la modernidad que proponía implicaba restablecer las diferencias de género que estaban amenazadas. Ortega proponía así un reforzamiento del orden de género en acuerdo con su propuesta general de una modernidad ordenada. El orden social, parece decirse Ortega, empieza siempre por el orden de género.

33 Rotundo, E. Anthony: "Body and Soul: Changing Ideals of American Middle-Class Manhood, 1770-1920", Journal of Social History, 16-4 (1983), p. 23. Ver también: Mosse, George L.: La imagen del hombre. La creación de la moderna masculinidad, Madrid, Talasa Ediciones, 2000, capítulo 3. Y más reciente: Forth, Christopher E.: Masculinity in the Modern West. Gender, Civilization and the Body, Nueva York, Palgrave Macmillan, 2008, capítulo 7; Tumblety, Joan: Remaking the Male Body. Masculinity and the Uses of Physical Culture in Interwar and Vichy France, Oxford, Oxford University Press, 2012.

34 Ortega y Gasset, José: La rebelión..., p. 191.

35 Ortega y Gasset, José: Qué es filosofia, p. 200.

36 Ortega y Gasset, José: Qué es filosofia, p. 200.

37 Ortega y Gasset, José: La rebelión ..., p. 190. 


\section{Unamuno. Una modernidad maternal}

El diagnóstico de Unamuno no puede ser más contrapuesto al descrito. Parece, de hecho, su reverso. Ya era abruptamente diferente cuando Unamuno, a finales del siglo XIX, abogaba por la europeización, porque ya entonces defendía, aunque con énfasis diferentes, una modernidad alternativa (y es en esta modernidad, como se ha dicho, donde se deben cifrar las diferencias que encontramos en el modelo de masculinidad $^{38}$ ). Y todavía será más lejana a la posición de Ortega cuando Unamuno asuma la divisa de la hispanización de Europa. Bajo la misma, y como señalara Ferrater Mora, no ha de buscarse un intento de imposición política o ideológica, sino, "la 'mostración' de lo que podría llamarse la «humanidad del hombre»" ${ }^{39}$. Es esta la que Unamuno confronta con el proceso de modernización y la que le conduce a renegar de la modernidad y su distintos corolarios, como la razón, la ciencia o la idea de progreso.

Unamuno realizó la exposición más completa de este pensamiento -que ya había iniciado en Vida de Don Quijote - en Del sentimiento trágico de la vida (1913). En esta obra, la defensa del sentido de la vida no se realiza por medio de la razón sino que, de hecho, en su opinión, "la razón es enemiga de la vida" y el progreso es definido como una enfermedad ${ }^{40}$. De lo que se trata, insistirá a lo largo de la obra, es de "la finalidad última de nuestra cultura toda"41. Y para ello, Unamuno recurrió a la religión católica y a lo que denominó filosofía española, pues, como afirmaba: "eso de que el individuo sea el fin del Universo lo sentimos muy bien nosotros los españoles"42. Puede así decirse que la afirmación de España o la reivindicación de la fe, que caracterizan gran parte de su obra, son también expresiones de ese rechazo de la modernidad en cuanto deshumanizadora. Lo sintetiza él mismo de una manera que puede entenderse como un resumen de todo el libro:

Aparéceseme la filosofía en el alma de mi pueblo como la expresión de una tragedia íntima análoga a la tragedia del alma de Don Quijote, como la expresión de una lucha entre lo que el mundo es según la razón de la ciencia nos lo muestra, y lo que queremos que sea, según la fe de nuestra religión nos lo dice ${ }^{43}$.

Son ideas herederas del humanismo barroco español, pero este barroquismo está lejos de ser extemporáneo. Muy al contrario, da plena actualidad a su obra y la engarza perfectamente con la de un conjunto de autores definidos como modernistas por el descentramiento al que someten a la cultura moderna ${ }^{44}$. Responden a un Zeitgeist, a un espíritu del tiempo, que se puede acuñar con el término de fin de siglo a

38 Un punto de vista diferente, dependiente del concepto de histeria, en Gabilondo, Joseba: "Histéricos con casta: Masculinidad y hegemonía nacional en la España de fin de siglo (para una arqueología feminista, torcida, marxista, postcolonial y posnacional del noventayochismo", en Raquel Medina y Barbara Zecchi (eds.): Sexualidad y escritura (1850-2000), Barcelona, Anthropos, 2002, pp. 132 y ss.

39 Ferrater Mora, José: Unamuno. Bosquejo de una filosofia, Madrid, Alianza, 1985, p. 91.

40 Unamuno, Miguel de: Del sentimiento trágico..., p. 220.

41 Unamuno, Miguel de: Del sentimiento trágico..., p. 261.

42 Unamuno, Miguel de: Del sentimiento trágico..., p. 492.

43 Unamuno, Miguel de: Del sentimiento trágico..., p. 503.

44 Ver Díaz Freire, José Javier: "La experiencia de la modernidad como una experiencia barroca", Historia Crítica, 56 (2015), pp. 137-160. 
condición de integrar en él un conjunto muy vasto de crisis ${ }^{45}$. Porque el mal del siglo describe tanto una crisis cultural, con el fin del positivismo y el realismo, como una crisis social y política, con las tendencias democratizadoras que denunciara Ortega, con la crisis del liberalismo, con el ascenso del movimiento obrero y de la denominada cuestión de la mujer. A lo que habría que añadir en el caso español la crisis de la Restauración y del imperio colonial. Todo ello otorga una tonalidad emocional específica al pensamiento finisecular, haciendo de sus representantes, y Unamuno es el más importante de ellos, intelectuales que podríamos denominar melancólicos. Su melancolía es la de la falta de sentido de la modernidad ${ }^{46}$. Unamuno lo expresa en esta definición del mal del siglo: "la famosa maladie du siècle... no era ni es otra cosa que la pérdida de la fe en la inmortalidad del alma, en la finalidad humana del universo" "47. Pero ante ello Unamuno no reacciona como Ortega intentando clausurar la modernidad, con un programa de restauración del orden social que es también un programa de restablecimiento del orden de género, sino explotando las posibilidades inscritas en el desorden finisecular para construir una modernidad más humana. Este proyecto exigía una reordenación de las relaciones de género.

Como se sabe, la generación finisecular se caracteriza porque diagnostica los males de España en términos psicológicos e históricos, es decir, con una interiorización que es también la de la masculinidad ${ }^{48}$. Unamuno es un buen ejemplo ${ }^{49}$. En sus ensayos En torno al casticismo, describe el carácter nacional a partir del hombre castizo castellano. "La sociedad civil que formaron estos hombres -dice- tomó de ellos carácter y sobre el de ellos reobró". Se trata pues de un problema situado en la constitución de la masculinidad pero no de un déficit de ella. De los rasgos que le atribuye, los más repetidos son los que definen el "espíritu castellano" como "disociativo, dualista, polarizador" 50 .

En el capítulo titulado "Sobre el marasmo actual de España", donde va explicando los problemas, Unamuno insiste en que en España "no hay verdadero espíritu de asociación", algo que, traducido a las relaciones de género, daba lugar al "brutalismo masculino, fuente de huraña grosería y de soeces desplantes", es decir, al desprecio de las mujeres. Ello daba lugar asimismo al "sometimiento de los hombres como po-

45 Para una caracterización del fin de siglo: Cerezo Galán, Pedro: El mal del siglo. El conflicto entre ilustración y romanticismo en la crisis finisecular del siglo XIX, Madrid, Biblioteca Nueva, 2003, pp. 25, 42 y passim. Ver también del mismo autor: Las máscaras de lo trágico. Filosofia y tragedia de Miguel de Unamuno, Madrid, Trotta, 1996.

46 Para la melancolía unamuniana ver: Díaz Freire, José Javier: "Miguel de Unamuno y Bilbao: la experiencia melancólica de la modernidad", Ayer, 98 (2015), pp. 21-44. Marichal ya inscribió el pensamiento de Unamuno dentro de lo que llamaba la "melancolía liberal", en Marichal, Juan: "La melancolía de un liberal: de Larra a Unamuno", en El secreto de España, Madrid, Taurus, 1995, pp. 99 y 103. Cerezo Galán extiende ese concepto de Marichal a Ortega y su obra La rebelión de las masas, en Cerezo Galán, Pedro: "De la melancolía liberal al ethos liberal. En torno a La rebelión de las masas de José Ortega y Gasset", Endoxa: Series filosóficas, 12 (2000), p. 317.

47 Unamuno, Miguel de: Del sentimiento trágico..., p. 475.

48 Estos rasgos y el calificativo de "generación finisecular" en Cerezo Galán, Pedro: El mal del siglo..., pp. 71-72 y 65. El desorden de género como una de las características principales del fin de siglo en: Showalter, Elaine: Sexual Anarchy: Gender and Culture at the Fin De Siècle, Londres, Virago, 1992, donde caracteriza el periodo por ese desorden y como una batalla entre los sexos y dentro de los sexos, pp. 8-9 y 18, entre otras.

49 Roberts afirma que Unamuno es el "principal intelectual finisecular". En Roberts, Stephen G.H.: "Unamuno y la emergencia del intelectual moderno en España", en Ana Chaguaceda Toledano (ed.): Miguel de Unamuno. Estudios sobre su obra II, Salamanca, Ediciones Universidad de Salamanca, 2005, p. 270. También afirma que es el primer intelectual moderno, en p. 271.

50 Unamuno, Miguel de: En torno al casticismo, Madrid, Biblioteca Nueva, 1996, pp. 116 y 104. 
lichinelas a caprichos e intrigüelas mujeriles"; aquí se avanzaba ya algo de la crítica al don Juan que veremos más adelante ${ }^{51}$. La solución propuesta por Unamuno es a estas alturas de 1895, como se sabe, la de la europeización dentro de lo rescatable de la tradición española, que encuentra en la mística y el humanismo. Como es sabido también, Unamuno continuaría reivindicando la mística aún después de abandonar la idea de la europeización. En Del sentimiento trágico de la vida, y en diálogo con Ortega, volvería a defender la mística afirmando que "acaso un día tengan que volver a ella, a buscar su alma, los pueblos a quienes Helena se la arrebatara con sus besos" 52 . Es, de nuevo, una afirmación del sentido de la vida frente a la racionalidad de la cultura moderna simbolizada, en este caso, por Helena. Que utilice una figura femenina para encarnar las ideas que han dado lugar a la modernidad enfatiza el poder significante del género.

En estos términos de género se puede decir, con un juego de palabras, que la regeneración que plantea es más bien una regenerización, que incluye una propuesta transgenérica. Se trasluce en este fragmento, en el que explica la mística barroca y describe a sus dos máximos representantes: "la mística-dice-idealizó, no lo eterno femenino, ni lo eterno masculino, sino lo eterno humano. Santa Teresa y San Juan de la Cruz, nada hombruna aquélla, nada mujeril éste, son excelentes tipos del homo que incluye en sí el vir y la mulier" "53. En Del sentimiento se aprecia mejor el alcance de estas palabras al elevar a estos santos como ejemplo de una religiosidad perfecta. En esta obra, Unamuno dedicó un espacio a explicar que la idea popular de que Dios es un hombre se debe a que la humanidad aparece escindida entre masculino y femenino, entre vir y mulier, y que eso mismo conduce a la "mariolatría". El culto popular a la Virgen respondería en su opinión a la necesidad de que "entre la feminidad en Dios". Algo que respalda taxativamente: "no podemos concebir al Dios vivo y entero como solamente varón" 54 .

El transgénero que propone Unamuno no es una confusión de géneros (algo que denunciará en diversas ocasiones) sino una redefinición de lo masculino y de lo femenino en la que cada uno integra al otro. La solución de Unamuno implica la ruptura de las oposiciones binarias, tanto las que oponen europeización con casticismo o hispanización, como las que enfrentan lo masculino con lo femenino ${ }^{55}$. Por eso, su evolución desde una posición europeizante a otra hispanizante es solo de énfasis o de expresión. Su rechazo de las oposiciones binarias será un rasgo de su pensamiento que se mantendrá durante toda su obra y, aunque se puede considerar como la causa de las muchas incomprensiones de su pensamiento y causa también de sus muy mencionadas paradojas, explica el enorme interés de su obra desde una perspectiva de género. Esta dimensión del problema le permitirá ofrecer unas propuestas en gran parte alternativas a las del debate al uso.

Para Unamuno, la búsqueda de una posición tercera respecto de las oposiciones binarias es tanto una cuestión teórica como metodológica. Desde el punto de vista

\footnotetext{
Unamuno, Miguel de: En torno al..., p. 161.

Unamuno, Miguel de: Del sentimiento trágico..., p. 486.

Unamuno, Miguel de: En torno al..., p. 134.

Unamuno, Miguel de: Del sentimiento trágico ..., p. 325-327.

55 Este rasgo ya lo señaló Cerezo Galán para explicar la posición de Unamuno sobre España con respecto al regeneracionismo. Dice que Unamuno parte "de la negatividad de las posiciones encontradas y de su mediación reflexiva, integradora, en un nuevo nivel que es, a la vez, memoria originaria y creatividad o progreso", en Cerezo Galán, Pedro: Las máscaras..., pp. 183-184.
} 
teórico, destaca su concepto de nimbo, que oponía al dualismo conceptista castellano del barroco. Desde el punto de vista metodológico, en En torno al casticismo confiesa que su método es el de la "afirmación alternativa de los contradictorios", que consistía en "hacer resaltar la fuerza de los extremos en el alma del lector para que el medio tome en ella vida" ${ }^{56}$. El origen hegeliano de esta propuesta es evidente y ha sido suficientemente resaltada por los investigadores. Y parece probarlo, además, el hecho de que ese medio, que no es sin embargo el punto medio entre las oposiciones, sea el resultado de la "lucha" entre estas últimas. Pero debemos retener que, si se trata de una dialéctica, no apunta tanto a su resolución en una síntesis como a la ubicación de lo disputado en un ámbito diferente. En palabras de Unamuno, la cuestión "consistirá en elevarles a otro campo distinto" 57 . Es decir, en romper la propia oposición binaria.

\section{Propuesta de Unamuno. La crítica alegórica de la masculinidad y la feminidad}

Desafiar el binarismo es la clave de bóveda sobre la que se construye todo el edificio de la propuesta unamuniana de solución del problema de España a través de la crítica del orden de género vigente y de su reforma. Esta propuesta puede evaluarse en las novelas mencionadas y, entre ellas, por medio de una lectura de Tres novelas ejemplares y un prólogo, Abel Sánchez y El otro. Quien conozca estas obras no dejará seguramente de sorprenderse, pues se caracterizan porque ofrecen una realidad desubicada de tiempo y espacio ${ }^{58}$. El mismo Unamuno tuvo que hacer frente en su tiempo a un comentario de Marañón que señalaba la desnudez material de sus relatos replicando que, "dando el espíritu de la carne, del hueso, de la roca, del agua, de la nube, de todo lo demás visible, se da la verdadera e íntima realidad". Y, aunque reconocía que en su drama Nada menos que todo un hombre había prescindido de todos los detalles de ubicación de sus personajes, reivindicaba que eran "tan de carne y hueso como los actores mismos". Y esto no solo, como podría parecer, porque Unamuno desafiaba abiertamente la diferencia entre realidad y ficción, sino porque reclamaba para sus personajes una cierta representatividad, la que le daba su propia ubicación en un mundo social determinado: "Yo no he sacado mis ficciones novelescas -o nivolescas- de mis libros -afirmó en el prólogo de Abel Sánchez-, sino de la vida social que siento y sufro -y gozo- en torno mío, y de mi propia vida". Y Unamuno tenía un profundo conocimiento de la realidad de su tiempo, tal y como muestran sus artículos de prensa y su epistolario ${ }^{59}$.

La desnudez de las novelas de Unamuno es un rasgo de estilo que hay que poner en relación con el carácter alegórico de las mismas. Y la representatividad que él mismo reclama no es realista sino alegórica. Seguimos aquí a Summerhill, quien afirmaba de forma categórica que "ha llegado la hora de reconocer la base alegórica de las novelas ejemplares de Unamuno", a la vez que colocaba a Unamuno a la "vanguardia de la

56 Unamuno, Miguel de: En torno al.., p. 51. El concepto de nimbo, en pp. 94 y ss., 99 y 104.

57 Unamuno, Miguel de: Miguel de Unamuno, artículos en "Las noticias” de Barcelona. Ed. Adolfo Sotelo Vázquez (ed.), Barcelona, Lumen, 1993, p. 318. Lo de la lucha en Unamuno, Miguel de: En torno al..., p. 95.

58 Marías, Julián: Miguel de Unamuno, Madrid, Espasa Calpe, 1980 (2ª ed.), p. 128.

59 Blanco Aguinaga decía que las Tres novelas estaban ancladas "en la más viva realidad de la España de los tiempos de Unamuno”, en Blanco Aguinaga, Manuel: “Aspectos dialécticos de las ‘Tres novelas ejemplares””, Revista de Occidente, 19 (1964), pp. 54-55. 
experimentación modernista en la novela" ${ }^{60}$. Esto mostraría una coherencia entre el fondo y la forma de su obra. El propio Unamuno reconoció que su modo de expresión no era realista, mientras ofrecía también una clave de interpretación al señalar que la "congoja unas veces trágica y otras cómica" de lo que llama la "conciencia de la propia personalidad" había inspirado "casi todos sus personajes de ficción" 61 . Pero aquí, la personalidad que parece preocupar a Unamuno es la que tiene que ver con las relaciones de género, porque sus personajes parecen regirse por estas normas, mientras se obscurecen otras que pudieran tener un contenido social más general o nacional.

Unamuno crea incluso un espacio específico para esas relaciones de género: $R e$ nada. Se trata de un espacio abstracto como el mismo topónimo se encarga de mostrar; o casi abstracto, porque en Nada menos se alude a la "vieja ciudad de Renada"62 y en San Manuel Bueno se recalca que es una "ciudad catedralicia"63. La primera mención a este lugar la encontramos en Abel Sánchez y la última en El hermano Juan, teniendo en cuenta que entre las primeras ediciones de ambas obras habían transcurrido diecisiete años. En medio aparece, al menos, en las obras ya citadas y en El otro, confirmando así la importancia simbólica que Unamuno quería otorgarle. Renada nombra un territorio donde solo rigen las relaciones de género. Es la demarcación donde los géneros se encuentran y entran en conflicto. Esto resulta evidente cuando El otro le recuerda a Laura, la protagonista femenina, que "llegada tú a Renada, te requerimos, casi te exigimos los dos de amores"64. Algo así ocurre también en Nada menos, aunque allí el que llega es Alejandro, el personaje masculino. Cuando este aparece, su oponente femenina es la "belleza oficial" y el motivo, junto con la catedral, para visitar el lugar: "Voy a Renada -decían algunos- a ver la Catedral y a ver a Julia Yáñez". Con la ponderación de su belleza, Unamuno quería resaltar a Julia como encarnación de la feminidad, el motivo del interés de Alejandro por ella: 'le hablaron de Julia, la hermosura monumental de Renada. ‘¡Hay que ver eso!' -se dijo-. Y luego que la vio: “¡Hay que conseguirla!'”,65.

Renada es también para Unamuno el ámbito donde las relaciones de género aparecen. Se lo dice casi literalmente Elvira a don Juan, en El hermano Juan, la obra junto con Niebla donde Unamuno estudia el personaje que encarna la masculinidad: "Ya estás aquí, en nuestra Renada y en esta casa, hoy posada y antaño tu hogar, el de tus padres, donde voló, ¡ensueño del alba!, nuestra común niñez”. Por si no fuera suficientemente claro, con las indicaciones al alba y la niñez, la exhortación de Elvira continúa: "cuando balbucientes, jugábamos ya a marido y mujer; nos acostaban, apretujaditos, en la misma cuna"66. Unamuno estiliza las relaciones de género y por eso sus novelas son una alegoría de estas relaciones en la España de entreguerras. En ellas, Unamuno realiza una crítica de la masculinidad y de la feminidad de su tiempo y ofrece una propuesta, si bien velada, de recomposición, que es, además, una propuesta de reorganización social.

60 Summerhill, Stephen J.: "Relectura de Nada menos que todo un hombre: alegoría de la creación", Cuadernos de la Cátedra Miguel de Unamuno, 40 (2005), p. 74.

61 Unamuno, Miguel de: San Manuel, p. 19. Del prólogo.

62 Unamuno, Miguel de: Tres novelas..., p. 93. El término aparece mencionado en cinco ocasiones.

63 Unamuno, Miguel de: San Manuel Bueno, mártir. Cómo se hace una novela, Madrid, Alianza Editorial, 1979 , p. 8. El término aparece mencionado en tres ocasiones.

64 Unamuno, Miguel de: El otro, p. 33. La otra mención al término en p. 21.

65 Unamuno, Miguel de: Tres novelas..., p. 101.

66 Unamuno, Miguel de: El otro, p. 93. 
El título de Tres novelas ejemplares y un prólogo describe efectivamente su contenido. Aunque el mismo Unamuno decía que el prólogo podía ser considerado como una cuarta novela, lo cierto es que incluye una serie de indicaciones que ayudan a reconocer el carácter alegórico de las restantes: como su insistencia en que "un símbolo puede hacerse hombre" ${ }^{67}$. Las tres novelas son: Dos madres, El marqués de Lumbría y Nada menos que todo un hombre. Las dos primeras representan la misma situación: el predominio en las relaciones de género de una mujer enteramente saturada de sí, es decir, una mujer que representa una forma de feminidad absoluta. Mientras que la tercera muestra, de forma simétrica, el predominio de un hombre, asimismo, saturado de sí, o sea de un hombre enteramente masculino.

En estas novelas, la idea de la completud genérica es expresada por Unamuno dotando a los personajes de una fuerte voluntad y de descendencia. Tener hijos es, por ello, el tema de la novela Dos madres. La protagonista es Raquel, quien ante la imposibilidad de tener un hijo decide tenerlo de forma vicaria a través de una joven llamada Berta. Para ello, promueve la relación entre su amante don Juan y Berta. Se trata de una maternidad sin concepción, exactamente el mismo caso que el de Gertrudis, la tía Tula, quien también tendrá un hijo de forma subrogada; aunque el motivo de Raquel no sea la castidad sino la infertilidad. Dice Summerhill que la alegoría se hace patente cuando los personajes están en una situación que trasciende los límites de la verosimilitud ${ }^{68}$. Aunque una maternidad de estas características ya no desafía la realidad contemporánea, como sí lo hacía en los años veinte, se debe buscar ahí la clave del significado de la novela. Para Unamuno la maternidad significaba la identidad de la mujer, lo que no implicaba la concepción: "Una mujer-decía- es siempre madre, aunque muera virgen" ${ }^{69}$. Ser madre significaba en esta novela ser enteramente mujer, pero representando, además, una feminidad moderna. Esto queda subrayado tanto en el caso de Raquel como de Tula, a través de la imposición de su voluntad sobre los demás; el libre ejercicio de la voluntad es un rasgo del sujeto moderno.

Al imponer su voluntad sobre Berta, Raquel demuestra que es enteramente mujer, pero también que su forma de feminidad se impone sobre la feminidad tradicional que Berta representa ${ }^{70}$. Es lo mismo que ocurre en la segunda novela El marqués de Lumbría entre Carolina y Luisa. Esta última, Luisa, muere, mostrando así el vencimiento de la feminidad tradicional. Por eso es posible afirmar que ambas novelas son especificaciones del mismo tema: el triunfo de la feminidad moderna. Berta no muere, pero sí es anulada en sus pretensiones de madre y en cuanto heredera de don Juan. Berta no consigue, pues, realizarse como sujeto moderno. No tiene existencia como tal sujeto.

Don Juan es la víctima principal del tipo de mujer total que Raquel y también Carolina, la heredera del marqués de Lumbría, representan. Por eso don Juan pregunta a Raquel: “¿por qué me has robado el cuerpo y el alma?”71. Es decir, le pregunta

67 Unamuno, Miguel de: Tres novelas ejemplares y un prólogo, Madrid, Espasa-Calpe, 1972, p. 21.

68 Summerhill, Stephen J.: "Relectura de...", p. 69.

69 La cita pertenece al "Discurso en los Juegos Florales de Murcia", que dio el 27 de marzo de 1932, citado en Sandoval Ullán, Antonio: "El concepto de mujer en el pensamiento de Miguel de Unamuno", Cuadernos de la Cátedra Miguel de Unamuno, 39 (2004), p. 51.

70 Sorprendentemente, Raquel ha llegado a ser interpretada como expresión del comportamiento instintivo, en Linares, Henry A.: "Maternal Instinct in Miguel de Unamuno's 'Dos Madres'”, Journal of Evolutionary Psychology, 24-3 (2003), pp. 164-166.

71 Unamuno, Miguel de: Tres novelas..., p. 47. 
por qué le ha privado de los dos asientos de la masculinidad, señalando así que una feminidad total es incompatible con la masculinidad o que al menos la degrada. Don Juan significa precisamente la degradación de la masculinidad. Para hacerlo patente, Unamuno priva a don Juan de descendencia. El don Juan es representado a menudo como un ser estéril, aunque en el caso de estas dos novelas tanto don Juan como Tristán, su alter ego, engendran un hijo. Ello no los convierte, sin embargo, en padres, en un movimiento que extrema de nuevo el juego de la alegoría. Unamuno lo deja claro diciendo de don Juan que "no tenía ningún apetito de paternidad"72.

Don Juan representa la degradación de la masculinidad, pero de la masculinidad tradicional, que como se sabe hunde sus raíces en la tradición caballeresca. Unamuno lo deja patente a través del personaje de Tristán, en El marqués de Lumbría. Ya la elección de su nombre hace referencia a los orígenes caballerescos de la masculinidad que quiere criticar. Tristán es el protagonista masculino de la leyenda Tristán e Isolda que Unamuno consideraba el Evangelio del ideal caballeresco ${ }^{73}$. Pero además, se puede considerar que el caso de Tristán explica el sometimiento del don Juan a la voluntad de Raquel. Recordemos que, en El marqués de Lumbría, Tristán entabla un noviazgo con Luisa, la segunda hija del marqués, pero tiene un desliz con Carolina, la mayorazga, que supondrá el sometimiento a esta. Carolina lo deja claro cuando le dice: "eres el hombre caído” y luego le explica: "¡fui yo quien te seduje, yo!... quien te ganó fui yo". También le dice que su "carne ha sido siempre muy flaca"74. Lo que contribuye a explicar su descenso a los infiernos. Y es que para Unamuno, y otros críticos del don Juan como Marañón -que ha estudiado Nerea Aresti-, el don Juan es una forma masculina feminizada precisamente por su pulsión por las mujeres; lo que supone invertir la valoración que en la cultura masculina tenía el acceso sexual al cuerpo de la mujer ${ }^{75}$.

El rasgo más característico del don Juan unamuniano es su falta de voluntad. Lo dice el narrador expresamente cuando explica que en don Juan había muerto la voluntad. O cuando Berta le pregunta: “¿Cuándo te vas a sentir hombre, Juan? ¿Cuándo has de tener voluntad propia?" Don Juan es consciente de ello, y precisamente por eso le pregunta a Raquel: "Por qué me has sorbido el tuétano de la voluntad?"76. Para Unamuno, la condición de hombre, lo que daba la hombría era la voluntad, pero como esta no aparecía vinculada a ninguna condición biológica sexual, la voluntad también estaba unida a la feminidad ${ }^{77}$. La voluntad era para él, en realidad, una con-

72 Unamuno, Miguel de: Tres novelas..., p. 39.

73 Unamuno, Miguel de: Del sentimiento trágico..., p. 384.

74 Unamuno, Miguel de: Tres novelas..., p. 89. Carolina también le dice: "eres el hombre caído. ¿Ves como te decía que naciste para fraile?”, en p. 90. Insiste aquí Unamuno en la idea de convertir simbólicamente al don Juan en fraile, algo que realizó en El hermano Juan.

75 Ver Aresti, Nerea: Médicos, donjuanes y mujeres modernas, Universidad del País Vasco, Bilbao, 2001, pp. 115 y ss.

76 Esta cita y la anterior en Unamuno, Miguel de: Tres novelas..., p. 47 y 42 . La ausencia de voluntad como rasgo del don Juan unamuniano en Zlotescu-Cioranu, Ioana: "Ejemplaridad de las tres novelas ejemplares de Unamuno". AIH. Actas III (1968), p. 957.

77 Unamuno expresa su rechazo a vincular la voluntad con la virilidad en diversas ocasiones negando la idea de Schopenhauer de que la voluntad esté ligada a los órganos sexuales; ver Unamuno, Miguel de: La agonía del cristianismo, Madrid, Espasa-Calpe, 2009 (1 ${ }^{\text {a }}$ edic. 1942), pp. 121-122. Dobón Antón señala la importancia de este pasaje en Dobón Antón, $\mathrm{M}^{\mathrm{a}}$ Dolores: "Matria contra patria en la trayectoria espiritual de Unamuno", Cuadernos de la Cátedra Miguel de Unamuno, 34 (1999), p. 88. La importancia que adquiere la voluntad a finales del siglo XIX para definir la masculinidad en Mosse, George L.: La imagen del hombre. La creación de la moderna masculinidad, Madrid, Talasa Ediciones, 2000, pp. 118-119. 
dición del sujeto. Donde quizás aparezca la falta de voluntad como impedimento de -toda- masculinidad de forma más clara, es en el personaje de Augusto en su obra Niebla. Augusto quiere ser un don Juan pero no lo consigue porque es incapaz de imponer su voluntad a las mujeres y a los otros hombres ${ }^{78}$.

Alejandro, el protagonista de Nada menos que todo un hombre, es por el contrario un héroe de la voluntad. Podría decirse que es todo voluntad y por ello representa el modelo de masculinidad opuesto a la del don Juan unamuniano ${ }^{79}$. Encarna el tipo más acabado, valga completo, de la masculinidad moderna ${ }^{80}$. Alejandro es todo masculinidad, lo lleva en el nombre. Unamuno, que era catedrático de griego, no podía bautiza Alejandro impunemente. Y Alejandro significa defensor del hombre. Es mucho por lo tanto lo que se juega en este personaje, porque Alejandro es, además, la masculinidad moderna que rechaza unos orígenes caballerescos. "Yo vengo de la nada, y no quiero entender esas andróminas del Código de honor", dice al declinar la propuesta de un duelo. Y lo reafirma diciendo: “¿Caballero yo? ¿Yo caballero?... ¡Nunca! ¡Yo no soy más que un hombre, pero todo un hombre, nada menos que todo un hombre!" 1 . El drama que presenta Unamuno es que esta masculinidad total, esta hipermasculinidad, no deja espacio vital a la feminidad encarnada por su mujer Julia.

Julia representa un modo de la feminidad que rechaza ser anulada, que busca incluso su realización, y que por eso también afirma su voluntad. Toda la relación entre Julia y Alejandro está atravesada por que este evita cualquier demostración de amor, sea a través de palabras cariñosas o manifestando celos. Esto hace sospechar a Julia que ella no es más que una forma de la realización de Alejandro como hombre. "No puedo ser su mujer sin que me quiera" 82 , se dice, mientras aumentan progresivamente las dudas de que tal amor exista realmente. Lo que la falta de amor implicaba, Unamuno lo deja claro, es una forma de objetualización de la mujer: Julia tiembla cuando oye a Alejandro llamar cosa a su primera mujer. La castidad de Gertrudis también sería una forma de rechazo de la objetualización, y en este sentido deben ser interpretadas las palabras de Tula: "¡Cuando una no es remedio es animal doméstico y la mayor parte de las veces ambas cosas a la vez!" ${ }^{83}$. Al final, la falta de demostraciones de amor, esto es, la falta de reconocimiento de una feminidad no cosificada, llevará a Julia al manicomio y posteriormente a la muerte. También morirá Alejan-

78 Este rasgo de Augusto ha sido señalado por Melgar Pernias, Yolanda: "La identidad masculina de Augusto como génesis del conflicto en Niebla de Miguel de Unamuno", Espéculo. Revista de Estudios Literarios, www.ucm. es/info/especulo/numero39/niebla.html, consultado el 4 de octubre de 2016, pp. 3-4. Después de la crisis de fin de siglo, la voluntad o la ausencia de la misma adquirió una gran importancia en Europa para la definición de las masculinidades nacionales; ver Tosh, Manliness and Masculinities, p. 119. y Sluga, Glenda: "Masculinities, Nations...", p. 241.

79 Feal señala que "su mundo no es más real que el de los donjuanes" y citando a Rof Carballo que Alejandro es un hombre "sectorializado", "parcial, incompleto", en Feal Deibe, Carlos: Unamuno: El Otro y Don Juan, Madrid, Cupsa Editorial, 1976, p. 173.

80 Feal, Carlos: "Psicoanálisis: Cómo se construye (y deconstruye) una identidad masculina: 'Morriña' de Pardo Bazán y 'Nada menos que todo un hombre' de Unamuno", en Francisco La Rubio Prado y José M. Pinto (coords.): El hispanismo en los Estados Unidos: discursos críticos, prácticas textuales, Madrid, Visor, 1999. Olson señala que Unamuno se había planteado titular como Todo un hombre la novela Amor y pedagogía, en referencia irónica a Avito Carrascal y su intento de hacer de su hijo un hombre completamente moderno, en Olson, Paul R.: The Great Chiasmus: Word and Flesh in the Novels of Unamuno, Indiana, Purdue University Press, 2003, p. 104.

81 Unamuno, Miguel de: Tres novelas..., pp. 119-121.

82 Unamuno, Miguel de: Tres novelas..., p. 106.

83 Unamuno, Miguel de: La tía Tula, p. 107. Unamuno explica que Julia "no se dio cuenta de su temblor; pero fue la palabra cosa aplicada por su marido a su primera mujer”, en Unamuno, Miguel de: Tres novelas..., p. 109. 
dro, quien, cuando Julia está ya muy enferma, se da cuenta de que no puede subsistir sin ella: " ¡Si no puedo ser tuyo, de la muerte!"

La insistencia de Unamuno en dar un final funesto a sus personajes masculinos llega al paroxismo en Abel Sánchez y en El otro, obras en las que los cuatro protagonistas mueren. En efecto, Unamuno liquida a Abel y a Joaquín, y a Cosme y Damián, porque estos representan distintos rasgos de la masculinidad vigente y Unamuno estaba convencido de que la conformación de la masculinidad de su tiempo estaba condenada al fracaso. Lo expresaba de forma inequívoca afirmando que "la virilidad marcha a su suicidio" ${ }^{85}$. Es cierto que este es también el tema de Niebla, donde Unamuno actualiza la figura del don Juan mostrando su imposibilidad en el contexto de principios del siglo XX. Pero si en esta nivola Augusto se suicida porque no consigue realizarse como don Juan, en Abel Sánchez y El otro la muerte aparece por la negatividad de la masculinidad para sí misma en cualquiera de sus expresiones contemporáneas ${ }^{86}$.

Lo anterior no significa que Unamuno olvide aquí las víctimas femeninas de la masculinidad, pero lo cierto es que, aunque las recuerda ${ }^{87}$, ambas obras insisten en el carácter letal de la masculinidad para los propios hombres. Por eso, Abel Sánchez comienza con la muerte de Joaquín y termina con este asumiendo la responsabilidad por el asesinato de su casi hermano: "Le he matado yo, yo -grita" 88 . Y por eso también El otro discurre entre la muerte de Damián y Cosme. La relación filial entre los dos hombres, sugerida en Abel Sánchez y confirmada en El otro, representa la relación de la masculinidad consigo misma. Abel y Joaquín no son hermanos, pero son "hermanos de crianza" 89 y Damián y Cosme son tan hermanos que son mellizos, y como tales indistinguibles incluso para sus mujeres. Así, dice Laura, la futura esposa de Cosme, que cuando ella llegó a Renada se encontró "con dos mellizos, Cosme y Damián Redondo, tan parecidos que no había modo de distinguirlos" $" 90$.

Del mismo modo, Unamuno resalta el parecido entre Damián y Cosme desarrollando una idea que ya estaba insinuada en Abel Sánchez. En efecto, en esta novela, aunque los protagonistas se presuman antitéticos, empiezan a confundirse hasta que Joaquín, que odia a Abel, reflexionando sobre ello, llega a preguntarse: "Mas ¿no es esto -se dijo luego- que me odio, que me envidio a mí mismo?"91. Este giro es particularmente importante porque Unamuno había presentado a los personajes como la encarnación de dos masculinidades diferenciadas, y con este movimiento viene a asumir que son la misma cosa. Este hecho es todavía más notable si reparamos en que Abel parece representar al don Juan y Joaquín tiene rasgos que insinúan una masculinidad más doméstica. El pesimismo de Unamuno parece afectar a todas las formas de ser hombre presentes en la sociedad española de su tiempo.

84 Unamuno, Miguel de: Tres novelas..., p. 140.

85 Unamuno, Miguel de: La agonía..., p. 122. Labanyi ya planteaba que Abel Sánchez representaba un conflicto sobre el significado de la masculinidad y entre diferentes modelos de la misma; en Labanyi, Jo: "Masculinity and the Family in Crisis: Reading Unamuno through Film Noir (Serrano De Osma's 1946 Adaptation of Abel Sánchez)", Romance Studies, 13-2 (1995), pp. 17 y ss.

86 Feal dice "El tema del otro y el de don Juan estructuran la obra de Unamuno", en Feal, Carlos: Unamuno..., p. 15.

$87 \mathrm{Al}$ menos en dos ocasiones, Joaquín, el otro protagonista de Abel Sánchez, le dice a su mujer Antonia que en la batalla entre hombres que ha librado con Abel, la "víctima" ha sido ella; en Unamuno, Miguel de: Abel Sánchez. Una historia de pasión, Madrid, Espasa-Calpe, 1971, pp. 52 y 151.

88 Unamuno, Miguel de: Abel Sánchez..., p. 147.

89 Unamuno, Miguel de: Abel Sánchez..., p. 13.

90 Unamuno, Miguel de: El otro, p. 22.

91 Unamuno, Miguel de: Abel Sánchez..., p. 90. 
El otro lleva el parecido entre Damián y Cosme hasta lo inverosímil, indicando que aquí está el núcleo de la alegoría y revelando que este drama puede ser leído como una especificación de Abel Sanchez; de hecho, el calificativo El otro que estructura todo el drama y le da título ya aparece en esta última, a pesar de que entre la aparición de una y otra obra transcurran catorce años ${ }^{92}$. El mensaje es el de la identidad de la masculinidad consigo misma: "el uno es el otro"93. Y por eso el carácter desgraciado de la masculinidad no podría ser atribuido a ninguna de sus encarnaciones en particular. Lo dice "El otro" cuando se pregunta: "¿Yo? ¿Asesino yo? ¿Pero quién soy yo? ¿Quién es el asesino? ¿Quién el asesinado? ¿Quién el verdugo? ¿Quién la víctima? ¿Quién Caín? ¿Quién Abel? ¿Quién soy yo, Cosme o Damián?" . La respuesta que se da a sí mismo es inequívoca: “¿Yo? Uno y el otro, Caín y Abel, ¡verdugo y víctima!"95.

La relación entre Joaquín y Abel -y por lo tanto entre Cosme y Damián- está atravesada por la envidia: Joaquín odia a Abel porque este consigue el amor de Helena que ambos deseaban; pero, en coherencia con la confusión de culpas, tampoco ese odio es unidireccional y, según avanza la novela, se descubre que también Abel es envidioso ${ }^{96}$. Al situar a Helena como causa del conflicto, Unamuno señala que de los componentes de la masculinidad, el más pernicioso es el que la hace depender del acceso sexual al cuerpo de las mujeres. De hecho, la masculinidad se cifra en ese acceso al cuerpo femenino y en el acceso no sexual al cuerpo de los hombres. Para que no quede duda de que el conflicto se debe solo a la mujer, Unamuno reitera este contenido en distintos diálogos. Así, Joaquín confiesa que a causa de Helena comenzó a "odiar a Abel con toda mi alma" y cuando su hija le inquiere si no habría otra causa, lo confirma taxativamente: “¿No había nada más que eso, nada más? ¡Qué yo sepa... no!" ${ }^{97}$. Por su parte, El otro, cuando hace repaso a las causas de su odio, incide también en la mujer pero añade, "desde pequeñito sufrí al verme fuera de mí mismo..., no podía soportar aquel espejo..., no podía verme fuera de mí" "98; lo que viene a decir que la causa del odio es interior a la propia conformación de la masculinidad.

\section{Conclusión}

En las novelas de Unamuno fallecen muchos personajes, sobre todo hombres. Se puede concluir que tanto en las Tres novelas como en Abel Sánchez y El otro, Unamuno busca exponer lo que, en términos de género, supondría para la sociedad española y europea el triunfo total de la feminidad y masculinidad modernas. Las novelas son una proyección del triunfo absoluto de esas nuevas relaciones de género. Y el balance que hace Unamuno de este proceso es el de su imposibilidad tal y como están constituidas, pero señalando sobre todo a la masculinidad; esta valoración aboca a la omnipresencia de la muerte en la trama de sus obras. La solución, fiel a su mé-

\footnotetext{
92 Por ejemplo en Unamuno, Miguel de: Abel Sánchez..., p. 90.

93 Unamuno, Miguel de: $E l$ otro, p. 28.

94 Unamuno, Miguel de: $E l$ otro, p. 25.

95 Unamuno, Miguel de: $E l$ otro, p. 26.

96 Unamuno identifica odio y envidia en un pasaje en el que se dice "todo odio es envidia", en Unamuno, Miguel de: Abel Sánchez..., p. 73. La envidia de Abel en p. 130 y 133.

97 Unamuno, Miguel de: Abel Sánchez..., p. 121.

98 Unamuno, Miguel de: El otro, p. 28.
} 
todo dialéctico de exposición de los contrarios, la deja Unamuno a juicio del lector, aunque esta debe buscarse en un punto medio entre todos los personajes. En una fusión de masculinidad y feminidad. Para encontrar dicha solución, no hace falta, sin embargo, esforzarse mucho. En el prólogo de 1920 a La tía Tula, decía Unamuno: "hablamos de patrias y sobre ellas de fraternidad universal, pero no es una sutileza lingüística el sostener que no pueden prosperar sino sobre matrias y sororidad" Unamuno entendía, a diferencia de Ortega, que la modernidad y por ende la nación construidas sobre valores masculinos no podían prosperar y necesitaban lo que denominaba "domesticidad sororial" 100 . Unamuno apostaba así por la proyección pública de los valores que atribuía a las mujeres. Ortega abogaba, por el contrario, por la proyección de los valores masculinos -lo que se expresaba en la diferente consideración que les merecía la figura del don Juan-, por eso sus proyectos de nación y su crítica a la modernidad difieren. Para el filósofo madrileño el problema de España y por ende de Europa radicaba en la indiferenciación o nivelación de los sexos, que cabía atribuir al idealismo característico de la modernidad occidental y que se expresaba, además, en la aparición de una masculinidad y de una feminidad inadecuadas: en la masculinidad del hombre-masa rebelde y en una feminidad incapaz de identificar la masculinidad conveniente a sus intereses. El diagnóstico de Ortega era así completamente distinto al de Unamuno, como también lo era la solución que proponía: el reforzamiento del orden de género. Para Ortega la superación de los problemas del período de entreguerras requería la clausura de la modernidad lo que implicaba asentarla sobre bases nuevas distintas del idealismo y, en el orden de género, exigía la restauración de una masculinidad y de una feminidad diferenciadas. Al vincular la suerte de la modernidad con la de las diferencias de género ambos autores apuntaban a la transcendencia del género para la conformación del mundo social, pero lo hacen desde posiciones enfrentadas. Ortega defendía una modernidad resignada en la que las diferencias sociales, incluidas las de género, no estuvieran amenazadas. Unamuno, en contraste, se posicionó del lado de una modernidad humanista, lo que le llevará a defender una masculinidad femenina: "hay hombres muy hombres, quiero decir muy viriles, que tienen corazón de madres, que son maternales" ${ }^{101}$. Tenía razón, hay hombres que queremos ser hombres maternales.

\section{Referencias bibliográficas}

Aresti, Nerea: "Masculinidad y nación en la España de los años 1920 y 1930", Mélanges de la Casa de Velázquez, 42-2 (2012), pp. 55-72.

- Médicos, donjuanes y mujeres modernas, Bilbao, Universidad del País Vasco, 2001.

Blanco Aguinaga, Manuel: “Aspectos dialécticos de las 'Tres novelas ejemplares”, Revista de Occidente, 19 (1964), pp. 51-70.

Cerezo Galán, Pedro: "De la melancolía liberal al ethos liberal. En torno a La rebelión de las masas de José Ortega y Gasset”, Endoxa: Series filosóficas, 12 (2000), pp. 313-340.

99 Unamuno, Miguel de: La tía..., p. 14. Dobón Antón ha señalado la importancia de los conceptos de matria y patria en la obra de Unamuno en un excelente artículo; en Dobón Antón, "Matria contra patria...", pp. 91 y 93 94.

100 Unamuno, Miguel de: La tía..., p. 15.

101 Unamuno, Miguel de: Epistolario americano: 1890-1936, Laureano Robles (ed.), Universidad de Salamanca, Salamanca, 1996, p. 517. 
- El mal del siglo. El conflicto entre ilustración y romanticismo en la crisis finisecular del siglo XIX, Madrid, Biblioteca Nueva, 2003.

- Las máscaras de lo trágico. Filosofía y tragedia de Miguel de Unamuno, Trotta, Madrid, 1996.

D’Ors, Eugenio: Lo barroco, Madrid, Tecnos, 1993.

Díaz Freire, José Javier: "La experiencia de la modernidad como una experiencia barroca", Historia Crítica, 56 (2015), pp. 137-160.

— "Miguel de Unamuno y Bilbao: la experiencia melancólica de la modernidad", Ayer, 98 (2015), pp. 21-44.

Dobón Antón, $\mathrm{M}^{\mathrm{a}}$ Dolores: "Matria contra patria en la trayectoria espiritual de Unamuno", Cuadernos de la Cátedra Miguel de Unamuno 34 (1999), pp. 75-96.

Dudink, Stefan, Hagerman, Karen y Tosh, John (eds.): Masculinities in Politics and War. Gendering Modern History, Manchester y Nueva York, Manchester University Press, 2004.

Minneapolis, Patrick H.: Ortega y Gasset and the Question of Modernity, University of Minnesota Press, 1989.

Feal, Carlos: "Psicoanálisis: Cómo se construye (y deconstruye) una identidad masculina: 'Morriña' de Pardo Bazán y 'Nada menos que todo un hombre' de Unamuno”, en Francisco La Rubio Prado y José M. Pinto (coords.): El hispanismo en los Estados Unido: discursos críticos, prácticas textuales, Madrid, Visor, 1999.

- Unamuno: El Otro y Don Juan, Madrid, Cupsa Editorial, 1976.

Ferrater Mora, José: Unamuno. Bosquejo de una filosofía, Madrid, Alianza, 1985.

Forth, Christopher E.: Masculinity in the Modern West. Gender, Civilization and the Body, Nueva York, Palgrave Macmillan, 2008.

Gabilondo, Joseba: "Histéricos con casta: Masculinidad y hegemonía nacional en la España de fin de siglo (para una arqueología feminista, torcida, marxista, postcolonial y posnacional del noventayochismo", en Raquel Medina y Barbara Zecchi (eds.): Sexualidad y escritura (1850-2000), Barcelona, Anthropos, 2002.

Labanyi, Jo: "Masculinity and the Family in Crisis: Reading Unamuno through Film Noir (Serrano De Osma's 1946 Adaptation of Abel Sánchez)", Romance Studies, 13-2 (1995), pp. 7-21.

Linares, "Maternal Instinct in Miguel de Unamuno's 'Dos Madres”", Journal of Evolutionary Psychology, 24-3/4 (2003).

Madariaga, Salvador de: Mujeres españolas, Madrid, Espasa-Calpe, 1991.

Marías, Julián: Miguel de Unamuno, Madrid, Espasa Calpe, 1980 (2ª ed).

Marichal, Juan: “La melancolía de un liberal: de Larra a Unamuno”, en El secreto de España, Madrid, Taurus, 1995.

Melgar Pernías, Yolanda: "La identidad masculina de Augusto como génesis del conflicto en Niebla de Miguel de Unamuno", Espéculo. Revista de Estudios Literarios, www.ucm.es/ info/especulo/numero39/niebla.html.

Mosse, George L.: La imagen del hombre. La creación de la moderna masculinidad, Madrid, Talasa Ediciones, 2000.

Olson, Paul R.: The Great Chiasmus: Word and Flesh in the Novels of Unamuno, Purdue University Press, Indiana, 2003.

Ortega y Gasset, José: El tema de nuestro tiempo, Madrid, Revista de Occidente, 1974 (1ª edic. 1923).

- España invertebrada, Madrid, Espasa-Calpe, 1984 (1ª ed. 1964).

- La rebelión de las masas, Barcelona, Planeta Agostini, 1985. 
- Obras Completas. Fundación José Ortega y Gasset, Madrid, Taurus, 2004.

- Qué es filosofía, Madrid, Revista de Occidente en Alianza Editorial, 1989.

Resser, Todd W.: Masculinities in Theory: An Introduction, Chichester Malden, Wiley-Blackwell, 2011.

Roberts, Stephen G.H.: "Unamuno y la emergencia del intelectual moderno en España”, en Ana Chaguaceda Toledano (ed.): Miguel de Unamuno. Estudios sobre su obra II, Salamanca, Ediciones Universidad de Salamanca, 2005.

Rotundo, E. Anthony: "Body and Soul: Changing Ideals of American Middle-Class Manhood, 1770-1920", Journal of Social History, 16-4 (1983), p. 23-38.

Salcedo, Emilio: "Unamuno y Ortega y Gasset, diálogo entre dos españoles", Cuadernos de la Cátedra Miguel de Unamuno, 7 (1956), p. 97-130.

Sánchez Barbudo, Antonio (ed.): Miguel de Unamuno, Barcelona, Crítica, 1980 (1ª edic. 1974).

Sandoval Ullán, Antonio: "El concepto de mujer en el pensamiento de Miguel de Unamuno", Cuadernos de la Cátedra Miguel de Unamuno, 39 (2004), pp. 27-60.

Showalter, Elaine: Sexual Anarchy: Gender and Culture at the Fin De Siècle, Londres, Virago, 1992.

Summerhill, Stephen J.: "Re-lectura de Nada menos que todo un hombre: alegoría de la creación”, Cuadernos de la Cátedra Miguel de Unamuno, 40 (2005), pp. 61-75.

Tumblety, Joan: Remaking the Male Body. Masculinity and the Uses of Physical Culture in Interwar and Vichy France, Oxford, Oxford University Press, 2012.

Unamuno, Miguel de: Abel Sánchez. Una historia de pasión, Madrid, Espasa-Calpe, 1971.

- Del sentimiento trágico de la vida en los hombres y en los pueblos y Tratado del amor de Dios, Madrid, Tecnos, 2005.

- En torno al casticismo, Madrid, Biblioteca Nueva, 1996.

- Epistolario americano: 1890-1936 (Laureano Robles, ed.), Salamanca, Universidad de Salamanca, 1996.

- La agonía del cristianismo, Madrid, Espasa-Calpe, 2009 (1 ${ }^{\text {a }}$ ed. 1942).

- Miguel de Unamuno, artículos en "Las noticias" de Barcelona. Ed. Adolfo Sotelo Vázquez (ed.), Barcelona, Lumen, 1993.

- San Manuel Bueno, mártir. Cómo se hace una novela, Madrid, Alianza Editorial, 1979.

- Tres novelas ejemplares y un prólogo, Madrid, Espasa-Calpe, 1972.

Yuval-Davis, Nira: Gender and Nation, Londres, SAGE Publications, 1997.

Zlotescu-Cioranu, Ioana: "Ejemplaridad de las tres novelas ejemplares de Unamuno", AIH. Actas III (1968). 